\title{
Three-dimensional desktop morphometric models for the Arctic Ocean floor
}

\author{
I.V. Florinsky $^{\text {a, }} *$ S.V. Filippov ${ }^{\text {a }}$ \\ ${ }^{a}$ Keldysh Institute of Applied Mathematics, Russian Academy of Sciences, Pushchino, Russia, iflor@mail.ru, fsv141@mail.ru \\ * Corresponding author
}

\begin{abstract}
We present results of the first phase of an ongoing project to create a system for three-dimensional (3D) geomorphometric modeling of the Arctic Ocean submarine topography. In this phase, we developed a testing, lowresolution desktop version of the system. We utilized a small, 5-km gridded digital elevation model (DEM) extracted from the International Bathymetric Chart of the Arctic Ocean (IBCAO) version 3.0. From the smoothed DEM, we derived digital models of several morphometric variables: horizontal, vertical, minimal, and maximal curvatures, catchment and dispersive areas, as well as topographic and stream power indices. To construct and visualize 3D morphometric models, we applied an original approach for 3D terrain modeling in the environment of the Blender package, free and open-source software. Finally, we present a series of 3D morphometric models with perspective views from the Atlantic, Eurasia, the Pacific, and North America. The experiment showed that the approach is efficient and can be used for creating next, desktop and web versions of the system for visualizing 3D morphometric models of higher resolutions.
\end{abstract}

Keywords: 3D visualization, digital terrain modeling, geomorphometry, bathymetry, IBCAO

\section{Introduction}

Geomorphometry deals with quantitative modeling and analysis of the topographic surface and relationships between topography and other natural and artificial components of geosystems (Hengl and Reuter, 2009; Florinsky, 2016, 2017). Geomorphometric methods are widely used to solve various multiscale problems of geomorphology, hydrology, soil science, geology, geophysics, geobotany, glaciology, oceanology, climatology, planetology, and other disciplines (Moore et al., 1991; Wilson and Gallant, 2000; Wilson, 2018). Digital models of morphometric variables derived from digital elevation models (DEMs) are used in such studies. The list of most popular morphometric variables (Table $1)$ includes several curvatures - horizontal $\left(k_{h}\right)$, vertical $\left(k_{v}\right)$, minimal $\left(k_{\min }\right)$, and maximal $\left(k_{\max }\right)$ ones, catchment $(C A)$ and dispersive $(D A)$ areas, topographic $(T I)$ and stream power $(S I)$ indices (Shary et al., 2002; Florinsky, 2016, 2017).

Submarine topography is one of the key factors determining the course and direction of processes occurring at the boundary between lithosphere and hydrosphere. Being a result of the interaction of endogenous and exogenous processes of different scales, submarine topography can reflect the geological structure of a territory. Thus, bathymetric DEMs are increasingly used for solving problems of marine geomorphology, geology, and biology. A comprehensive review on marine geomorphometry was presented by Lecours et al. (2016).

Studies of the submarine topography of the Arctic Ocean occupy a special place. This is due, among other things, to the problem of justifying national outer limits of the Arctic shelf (Mayer, 2016). Another factor is the search for mineral deposits, for example, hydrocarbons (Grantz and Patrick, 2012).

Advances in computer graphic and geoinformation technologies opens up new possibilities in constructing three-dimensional (3D) images of the world. It is obvious that $3 \mathrm{D}$ representation of morphometric data can help to better understand relationships between topographic characteristics and objects under study.

We develop a system for 3D geomorphometric modeling of the Arctic Ocean floor (Florinsky et al., 2018). In this paper, we present results of the first phase of the project: a testing, low-resolution desktop version of the system.

\section{Materials and Methods}

\subsection{Geomorphometric modeling}

We used a small, testing DEM extracted from the 500-m gridded DEM IBCAO_V3_500m_RR, which belongs to a data set of the International Bathymetric Chart of the Arctic Ocean, IBCAO version 3.0 (IBCAO, 2012; Jakobsson et al., 2012).

The testing DEM describes a territory measuring about $5,800 \mathrm{~km} \times 5,800 \mathrm{~km}$, which includes the Arctic Ocean basin and adjacent regions of Eurasia and North America. It is based on the $5-\mathrm{km}$ square grid (a $1161 \times 1161$ depth/elevation matrix; $1,347,911$ points). Depths/elevations range from $-5,520 \mathrm{~m}$ to $5,110 \mathrm{~m}$. The testing DEM is presented in the polar stereographic 


\begin{tabular}{|c|c|}
\hline Variable & Definition and interpretation \\
\hline$k_{h}$ & $\begin{array}{l}\text { A curvature of a normal section tangential } \\
\text { to a contour line at a given point of the } \\
\text { surface. } k_{h} \text { is a measure of flow } \\
\text { convergence and divergence. Gravity- } \\
\text { driven lateral flows converge where } \\
k_{h}<0 \text {, and diverge where } k_{h}>0 . k_{h} \\
\text { mapping reveals ridge and valley spurs. }\end{array}$ \\
\hline$k_{v}$ & $\begin{array}{l}\text { A curvature of a normal section having a } \\
\text { common tangent line with a slope line at } \\
\text { a given point of the surface. } k_{v} \text { is a } \\
\text { measure of relative deceleration and } \\
\text { acceleration of gravity-driven flows. They } \\
\text { are decelerated where } k_{v}<0 \text {, and are } \\
\text { accelerated where } k_{v}>0 . k_{v} \text { mapping } \\
\text { allows revealing terraces and scarps. }\end{array}$ \\
\hline$k_{\min }$ & $\begin{array}{l}\text { A curvature of a principal section with } \\
\text { the lowest value of curvature at a given } \\
\text { point of the surface } k_{\min }>0 \\
\text { corresponds to local convex landforms, } \\
\text { while } k_{\min }<0 \text { relates to elongated } \\
\text { concave landforms (e.g., troughs and } \\
\text { valleys). }\end{array}$ \\
\hline$k_{\max }$ & $\begin{array}{l}\text { A curvature of a principal section with the } \\
\text { highest value of curvature at a given point } \\
\text { of the surface. } k_{\max }>0 \text { corresponds to } \\
\text { elongated convex landforms (e.g., ridges), } \\
\text { while } k_{\max }<0 \text { relate to local concave } \\
\text { landforms. }\end{array}$ \\
\hline$C A$ & $\begin{array}{l}\text { An area of a closed figure formed by a } \\
\text { contour segment at a given point of the } \\
\text { surface and two flow lines coming from } \\
\text { upslope to the contour segment ends. } C A \\
\text { is a measure of the contributing area. }\end{array}$ \\
\hline$D A$ & $\begin{array}{l}\text { An area of a closed figure formed by a } \\
\text { contour segment at a given point of the } \\
\text { topographic surface and two flow lines } \\
\text { going down slope from the contour } \\
\text { segment ends. } D A \text { is a measure of a } \\
\text { downslope area potentially exposed by } \\
\text { flows passing through a given point. }\end{array}$ \\
\hline$T I$ & $\begin{array}{l}\text { A ratio of catchment area to slope at a } \\
\text { given point of the topographic surface. A } \\
\text { measure of the extent of flow } \\
\text { accumulation. }\end{array}$ \\
\hline$S I$ & $\begin{array}{l}\text { A product of catchment area and slope at } \\
\text { a given point of the topographic surface. } \\
\text { A measure of potential flow erosion and } \\
\text { related landscape processes. }\end{array}$ \\
\hline
\end{tabular}

Table 1. Definitions and interpretations of some morphometric variables (Shary et al., 2002; Florinsky, 2016, 2017).

projection (Florinsky et al., 2018).

To suppress high frequency noise in the testing DEM, it was smoothed. From the smoothed DEM, we derived digital models of several local morphometric variables (i.e., $k_{h}, k_{v}, k_{\min }, k_{\max }, C A, D A, T I$, and $S I$ ). We selected these variables because they have clear physical and mathematical sense (Table 1). Each of them describes a particular property of the topographic surface; for their definitions, formula, and interpretations, see (Florinsky, 2016, 2017). Curvatures were derived using a finitedifference method; $C A$ and $D A$ were calculated using a flow-routing algorithm; $T I$ and $S I$ were derived by combination of a flow-routing and finite-difference algorithms (Florinsky, 2016). Here we applied the LandLord software (Florinsky, 2016).

Morphometric maps were produced from these models (some of these maps were earlier published; see (Florinsky et al., 2018)). The maps were then used as morphometric textures for overlaying on 3D models (see below).

\subsection{D modeling}

To construct 3D morphometric models, we applied an original approach for $3 \mathrm{D}$ terrain modeling in the environment of Blender (Blender Foundation, 20032018). Blender is a free, open-source multiplatform software originally designed for 3D modeling, visualization, and animation (Simonds, 2013). Currently, Blender is systematically used for 3D scientific visualization (Kent, 2015; Filippov, 2018).

The Blender-based approach for 3D terrain modeling (Florinsky and Filippov, 2018) includes the following main steps:

1. Automatic creating a polygonal object from a DEM.

2. Selecting an algorithm to model the $3 \mathrm{D}$ geometry.

3. Selecting a vertical exaggeration scale.

4. Selecting types, parameters, a number, and positions of light sources.

5. Selecting methods for generating shadows.

6. Selecting a shading method for the $3 \mathrm{D}$ model.

7. Selecting a material for the 3D model surface.

8. Overlaying a texture on the 3D model.

9. Setting a virtual camera(s).

10. Rendering the 3D model.

First, we created a polygonal object from the smoothed testing DEM, which includes 1,347,911 vertices and $1,345,600$ faces.

Second, the 3D geometry of the polygonal object was modeled applying a subdivision algorithm by Catmull and Clark (1978), with the double subdivision of faces and edges.

Third, we selected an $80^{\times}$vertical scale exaggeration to enhance visual perception of topographic features. We set such a large factor because the elevation difference is only around $10.6 \mathrm{~km}$ within the area measuring about $5,800 \mathrm{~km} \times 5,800 \mathrm{~km}$.

One or two light sources are not enough for adequate visual perception of such a topographically diverse territory. So, to illuminate the 3D model, we used five point light sources with different intensities. Shadows from all light sources were turned off.

Then, a 'rasterized' appearance of the 3D model was 


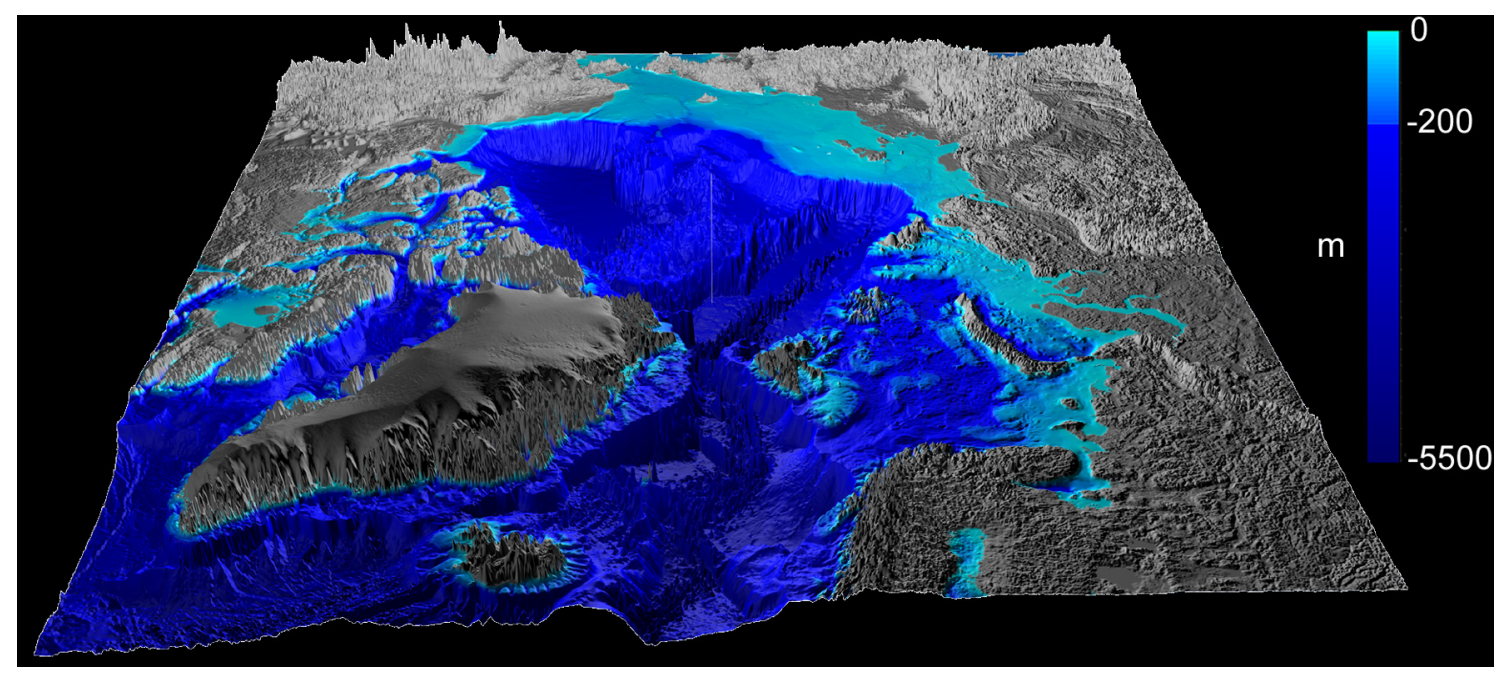

Figure 1 . The 3D model of the depth. The perspective view from the Atlantic.

smoothed using a shading algorithm by Phong (1975).

For the 3D surface, we used a material with the Lambertian diffuse reflection (Horn, 1981) combined with a specular reflection (Cook and Torrance, 1982).

Next, the monochromic 3D model was overlaid by color morphometric textures. Notice that we overlaid the textures on the submarine portion of the 3D model only.

Four virtual cameras were set to provide perspective views from the Atlantic, Eurasia, Pacific, and North America. Cameras had a conditional sensor size of $32 \mathrm{~mm}$ (full frame) and a focal length of $35 \mathrm{~mm}$.

Finally, off-line rendering of 3D models was performed by the Blender Render engine.

\section{Results and Discussions}

Figures 1-3 display examples of the produced 3D morphometric models.

One can observe the obvious generalization and smoothness of the ocean floor. This is due to the low resolution of the testing DEM and several smoothing procedures applied in geomorphometric and 3D modeling (see Section 2). However, 3D models clearly show the main features of the submarine topography, which are manifested according to the physical and mathematical sense of a particular morphometric variable (Table 1).

In particular, the 3D model of $k_{h}$ (Figure 2) represents divergence and convergence areas $\left(k_{h}>0\right.$ and $k_{h}<0$, correspondingly) of gravity-driven, near-bottom flow of substances. Geomorphologically, these areas relate to submarine ridge and valley spurs (yellow and blue patterns, correspondingly).

The 3D model of $k_{v}$ (Figure 3) shows areas of relative deceleration and acceleration $\left(k_{v}>0\right.$ and $k_{v}<0$, yellow and blue patterns, correspondingly) of gravity-driven, near-bottom flow of substances. Geomorphologically, $k_{v}$ allows revealing submarine terraces, scarps, and similar elements of submarine topography.

The used approach for 3D terrain modeling is flexible. In case of scientific or aesthetic necessity, one can easily change a set of rendering parameters or choose a desired ones, for instance, to add virtual light sources, to change lighting angles of a 3D model, to enable the display of shadows, to change properties of a $3 \mathrm{D}$ surface material (e.g., to disable glare or to change a method of their calculation). Changing position and orientation of virtual cameras, one can explore a 3D model from any angle.

\section{Conclusions}

The experiment to develop a testing, desktop lowresolution system for 3D geomorphometric modeling of the Arctic Ocean floor demonstrated that the used approach is functional. It can be applied for creating a next desktop version of the system providing visualization for models of higher resolutions (up to 500 $\mathrm{m}$, that is, the original resolution of the square-gridded version of IBCAO 3.0).

A final, web version of the system will also include $3 \mathrm{D}$ morphometric models of submarine topography with resolutions of up to $500 \mathrm{~m}$.

The system will provide:

1. Storage of a big DEM of the ocean floor.

2. Derivation of digital models for eighteen morphometric variables from this DEM.

3. Interactive multiscale $3 \mathrm{D}$ visualization of the obtained models.

4. Free access to this information via Internet, with 3D real-time visualization online.

\section{Acknowledgements}

The study is supported by the Russian Foundation for Basic Research, grants \#\# 18-07-00223 and 18-07-00354.

\section{References}

Blender Foundation. (2003-2018). Blender. Stichting Blender Foundation, Amsterdam, https://www.blender.org.

Catmull, E. and Clark, J. (1978). Recursively Generated B-Spline Surfaces on Arbitrary Topological Meshes. Computer-Aided Design, 10: 350-355.

Cook, R.L. and Torrance, K.E. (1982). A Reflectance 


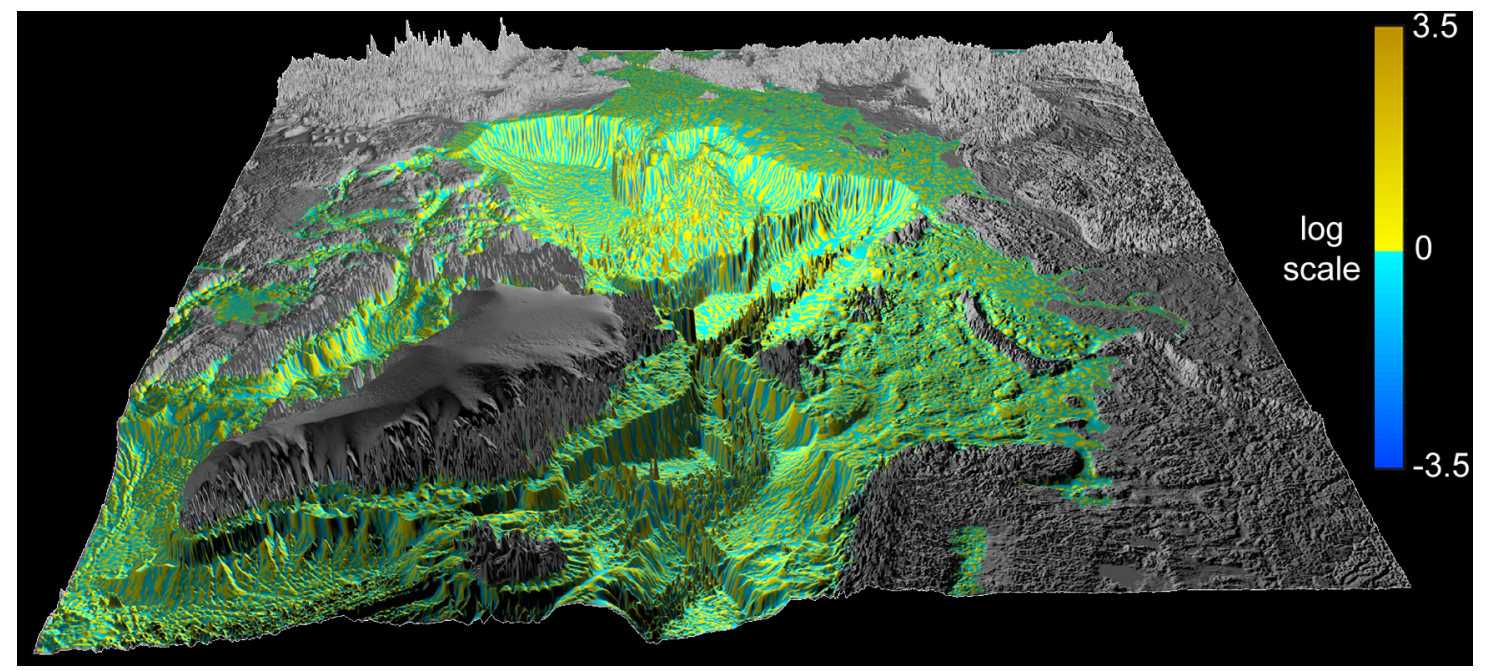

Figure 2. The 3D model of the: horizontal curvature. The perspective view from the Atlantic.

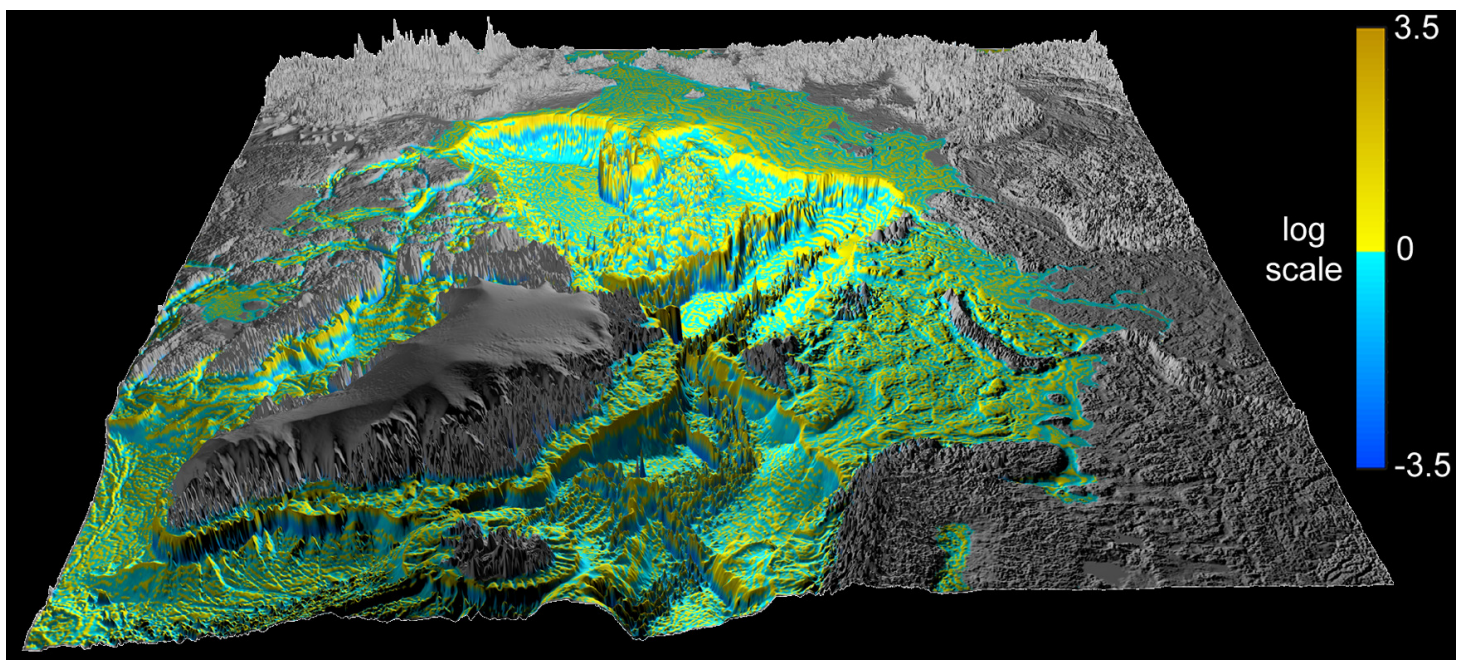

Figure 3. The 3D model of the vertical curvature. The perspective view from the Atlantic.

Model for Computer Graphics. ACM Transactions on Graphics, 1: 7-24.

Filippov, S.V. (2018). Blender Software Platform as an Environment for Modelling Objects and Processes of Science Disciplines. KIAM Preprints, 230: 1-42 [in Russian, with English abstract].

Florinsky, I.V. (2016). Digital Terrain Analysis in Soil Science and Geology. 2nd ed. Academic Press, Amsterdam.

Florinsky, I.V. (2017). An Illustrated Introduction to General Geomorphometry. Progress in Physical Geography, 41: 723-752.

Florinsky, I.V. and Filippov, S.V. (2018). ThreeDimensional Terrain Modeling: Application of the Blender Package. In: Tikunov, V.S. (Ed.), InterCarto/InterGIS 24: Proceedings of the International Conference, 19-21 July 2018, Petrozavodsk, Russia, Pt. 2. Karelian Research Center, Russian Academy of Sciences, pp. 250-261 [in Russian, with English abstract].
Florinsky, I.V., Filippov, S.V., Abramova, A.S., Zarayskaya, Y.A. and Selezneva, E.V. (2018). Towards Geomorphometric Modelling of the Topography of the Arctic Ocean Floor. In: Bandrova, T. and Konečný, M. (Eds.), Proceedings of the 7th International Conference on Cartography \& GIS, 18-23 June 2018, Sozopol, Bulgaria, Vol. 1. Bulgarian Cartographic Association, Sofia, pp. 166-173.

Grantz, A. and Patrick, E. (2012). Petroleum Prospectivity of the Canada Basin, Arctic Ocean. Marine and Petroleum Geology, 30: 126-143.

Hengl, T. and Reuter, H.I. (Eds.) (2009). Geomorphometry: Concepts, Software, Applications. Elsevier, Amsterdam.

Horn, B.K.P. (1981). Hill Shading and the Reflectance Map. Proceedings of IEEE, 69: 14-47.

IBCAO. (2012). International Bathymetric Chart of the Arctic Ocean (IBCAO) Version 3.0. National Centers for Environmental Information, NOAA, http://www.ngdc.noaa.gov/mgg/bathymetry/arctic/ibcao 
version3.html.

Jakobsson, M., Mayer, L., Coakley, B., Dowdeswell, J.A., Forbes, S., Fridman, B., Hodnesdal, H., et al. (2012). The International Bathymetric Chart of the Arctic Ocean (IBCAO) Version 3.0. Geophysical Research Letters, 39: L12609.

Kent, B.R. (2015). 3D Scientific Visualization with Blender ${ }^{\circledR}$. Morgan \& Claypool, San Rafael, CA.

Lecours, V., Dolan, M.F.J., Micallef, A. and Lucieer, V.L. (2016). A Review of Marine Geomorphometry, the Quantitative Study of the Seafloor. Hydrology and Earth System Sciences, 20: 3207-3244.

Mayer, L.A. (2016). The Arctic Continental Shelf and Its Evolving Morphologic Context. In: Nordquist, M.H., Moore, J.N. and Long, R. (Eds.), Challenges of the Changing Arctic: Continental Shelf, Navigation, and Fisheries. Brill Nijhoff, Leiden, pp. 17-41.

Moore, I.D., Grayson, R.B. and Ladson, A.R. (1991). Digital Terrain Modelling: A Review of Hydrological, Geomorphological and Biological Applications. Hydrological Processes, 5: 3-30.

Phong, B.T. (1975). Illumination for Computer Generated Pictures. Communications of ACM, 18: 311-317.

Shary, P.A., Sharaya, L.S. and Mitusov, A.V. (2002). Fundamental Quantitative Methods of Land Surface Analysis. Geoderma, 107: 1-32.

Simonds, B. (2013). Blender Master Class: A Hands-On Guide to Modeling, Sculpting, Materials, and Rendering. No Starch Press, San Francisco, CA.

Wilson, J.P. (2018). Environmental Applications of Digital Terrain Modeling. Wiley-Blackwell, Chichester.

Wilson, J.P. and Gallant, J.C. (Eds.) (2000). Terrain Analysis: Principles and Applications. Wiley, New York. 